\title{
The Impact of Gender Differences on Adoption of Information Technology and Related Responses: A Review
}

\author{
Abubaker Shaouf* and Omar Altaqqi \\ Al-Zintan University, Libya
}

*Corresponding author: Abubaker Shaouf, Department of Management, Faculty of Accounting, Al-Zintan University, Libya. E-mail address: ashaouf@gmail.com

\begin{abstract}
Over the recent years, there has been a significant increase in the number of women belonging to the Internet population. With this increase, researchers have begun to investigate the role of gender in information technology (IT) adoption and its related innovations, including e-commerce. Despite the large body of research on the topic, we know of no work that specifically reviews the literature regarding gender differences in these domains. To address this gap, we systematically reviewed the recent literature (in the period 2000-2017) regarding gender differences in IT adoption and six related behaviors and responses: online shopping adoption, online trust, attitude and satisfaction with e-commerce, website design preferences, and information processing strategies. Findings from the current review indicated that, in general, men are more likely to try a new IT and shop online than women, although the findings have been far somehow contradictory. Overall, men tend to have more positive evaluations of websites than women. According to the current review, gender differences play an important role in moderating certain relationships between different influencing variables. We highlight areas requiring future research and discuss the findings in the context of several theoretical perspectives.
\end{abstract}

Key words: Gender Difference, Gender Gap, Information Technology, e-Commerce, Online Shopping, Buying Decision, Trust, Information Processing 


\section{Introduction}

In the 1990s when the dotcom bubble began, $95 \%$ of the Internet users were males (Morahan-Martin, 1998; Weiser, 2000; Wilder et al., 1985). In 2017, the International Telecommunications Union reports that the proportion of men using the internet is $12 \%$ higher than the proportion of women; this gender gap widens to $32.9 \%$ in the least developed countries. As a result, gender differences in computer-mediated services have occupied the attention of researchers and practitioners alike in recent years (Beldad et al., 2016; Faqih and Jaradat, 2015; Lian and Yen, 2014; LiebanaCabanillas et al., 2014;Lin and Hsieh, 2016; Pengnate and Sarathy, 2017; Rodgers and Harris, 2003; Shaouf et al., 2016; Slyke et al., 2010; Zhang et al., 2014).

Despite the considerable amount of the literature addressing gender differences in various IT contexts, we know of no specific work that outlines the history of gender differences in the fields of IT and its innovations, including e-commerce (MeyersLevy and Loken, 2015). Therefore, this paper aims to provide guidelines for IT managers and e-marketers by reviewing the available literature regarding gender differences in IT adoption and six related behaviors and responses: online shopping adoption, online trust, attitude and satisfaction with e-commerce, website design preferences, and information processing styles. In this article, we focus on the period 2000-2017, as many gender differences have been emerged during this period (Cyr, 2014; Meyers-Levy and Loken, 2015).

Recognizing the importance of this review, Cyr (2014) argued that identifying and clarifying differences between men and women in the use of IT-related innovations have not only theoretical merit, but practical purpose as well. Rodgers and Harris (2003, p. 322) also argue: "Because web sites tend to be targeted to one or both genders, attempting to understand the different ways that males and females perceive online shopping is appropriate". Equally, Tsichla et al. (2014, p.2) have also emphasized that "a thorough understanding of gender-specific evaluations and desires pertaining to web design is paramount".

Among the many characteristics that impact the use of e-commerce is gender (Van Slyke et al., 2010). Due to its identifiability and accessibility, gender has been found, and continues to be, a useful demographic factor used to divide market segment. Gender is also considered to be a variable that can be easily combined into information management and communication systems (Riedl et al., 2010). Thus, the completion of this article will provide IT managers and e-marketers with much insight into how to develop online communication strategies among men and women, as men and women evaluate information differently (Putrevu, 2010).

The organization of this paper is as follows. We start with explaining the methodology used in the current review of the literature. We then outline the empirical research conducted on gender differences in several dimensions, including IT adoption, online shopping adoption, online trust, attitude and satisfaction with ecommerce, and information processing styles. Finally, we provide a summary of the whole article, highlighting areas requiring future research.

International Journal of Management and Applied Research, 2018, Vol. 5, No. 1 


\section{Methodology}

Mulrow (1994) argued that conducting systematic literature reviews is deemed as a "fundamental scientific activity" (p, 597). In order to review the available literature on gender differences in IT adoption and its related behaviors, a number of steps were followed, as proposed by Tranfield et al. (2003). In the first step, the author identified the objectives of - and needs for - reviewing the existing literature. The major objective of this review was to provide guidelines for researchers and practitioners that outline all gender differences in the context of IT and five related aspects, namely: online shopping adoption, online trust, attitude and satisfaction with ecommerce, website design preferences, and information processing styles.

Following to that, a comprehensive plan for the review was made by selecting a set of databases, as well as identifying several keywords and search terms. The majority of published articles analyzed in this paper were searched in Google Scholar, in addition to several large databases (e.g. Science Direct, Sage, and Emerald). It is believed that a considerable amount of scientific material is published through these databases (Cyr, 2014; Meyers-Levy and Loken, 2015). Thus, they were considered to be likely sources to provide useful material for the purpose of this article.

In the third step, all published papers addressing gender differences were searched for, in which a large number of journal papers were found. In the following step, the abstract of each selected article was carefully reviewed. Accordingly, the decision regarding the inclusion or exclusion of the article was made. If an article was considered to be related to the current paper, it was selected for further review. If information provided by the abstract was not enough to make a decision, the article was selected for further evaluation as well. All selected articles in the previous phase were further filtered by reviewing full-text articles. As a result, any article that was not related to the purpose of this paper was excluded.

In order to minimize human biases and errors, literature reviews usually employ data extraction methods, which summarize information of the selected articles (Tranfield et al., 2003). In this regard, researchers are always advised to avoid including "all studies that meet broad standards in terms of independent and dependent variables, avoiding any judgments of quality." (Slavin, 1986, p. 6). The current review analyzes peer-reviewed articles published in top international journals in the field of IT, business, and education: MIS Quarterly, Journal of Management Information Systems, Information and Management, Computers in Human Behavior, Journal of Business Research, Journal of Marketing, International Journal of Information Management, Behavior \& Information Technology,Computers \& Education, andJournal of Consumer Behavior.

After a comprehensive literature review on the mentioned topics, some significant gaps in the literature were clearly identified. Figure 1 illustrates the breakdown of sources that contributed to the literature review.

International Journal of Management and Applied Research, 2018, Vol. 5, No. 1 
Figure 1: Summary of Sources Contributing to the Systematic Review

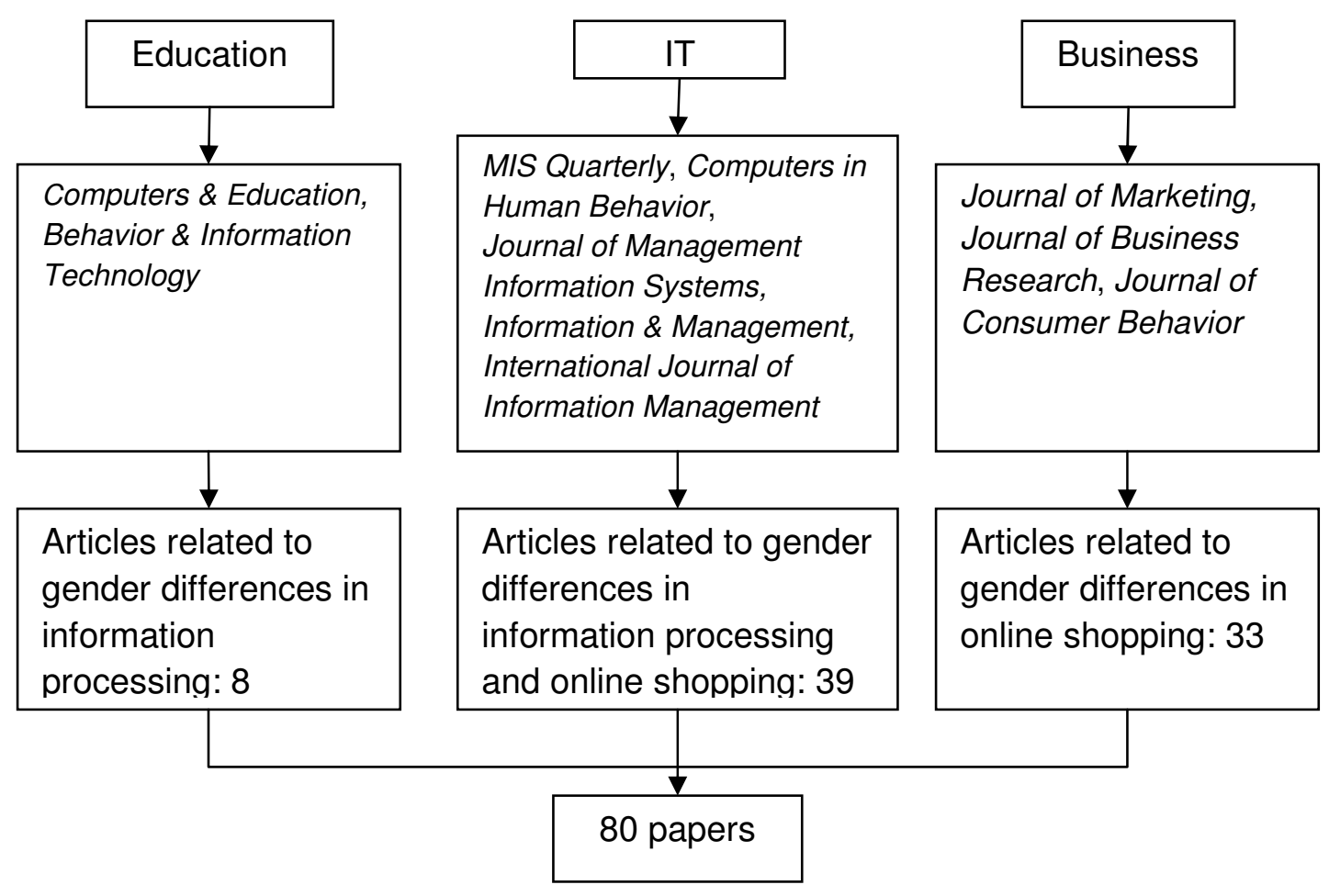

\section{Literature review}

\subsection{Gender differences and IT adoption}

The term "gender" refers to whether an individual is genetically and biologically male or female (Wilson, 2002). The influence of gender difference on IT adoption has attracted considerable attention in the literature (Awad and Ragowsky, 2008; Park, 2015; Porter et al., 2012; Shaouf et al., 2016; Sun et al., 2010). In the early 2000s, the attitude towards IT varies according to gender (Venkatesh and Morris, 2000) and Internet users were fundamentally dominated by males rather than females (Weiser, 2000). During the internet boom in the end of 1990s and early 2000s, males were more experienced than females with computer programming and games (Schumacher and Morahan-Martin, 2001).

The important investigation of Van Slyke et al., (2002) has also established that, men are more likely to try a new thing and/or technology in comparison with women. As concluded by Braak (2004), males felt more confident with computers than females did. Furthermore, women and men were found to have different perceptions towards communication technologies such as email (Phillip and Suri, 2004).

Conversely, Bigne et al. (2005) reported no significant difference between males and females in using mobile technology in internet-related activities in Spain. In the same way, Serenko et al., (2006) found that male and female users follow a similar pattern in forming beliefs about new information technologies. 
Sanchez-Franco (2006) provided in-depth analysis of how men and women differ in their web acceptance and usage processes. Similarly, Ong and Lai (2006) examined differences between males and females in relation to perceptions and relationships among factors affecting e-learning acceptance. The findings indicated that males' perceived usefulness, perceived ease of use, and behavioral intention to use e-learning were all higher than females'. Also, females were found to be more affected by perceptions of computer self-efficacy and ease of use (Ong and Lai, 2006). They also noted that males' use decisions were more influenced by their perception of usefulness of e-learning.

In the same context, some researchers (e.g., Amin et al., 2015; Awad and Ragowsky, 2008; Terzis and Economides, 2011;Venkatesh and Morris, 2000) examined gender differences related to the Technology Acceptance Model (TAM). Generally, the findings of these studies indicated that perceived usefulness (PU) is more important for men, while perceived ease of use (PEOU) is more important for women. A number of other empirical studies have examined users' perceptions of IT, with significant gender differences (e.g. Okazaki and Hirose, 2009; Putrevu, 2010; Shen et al., 2010).

In the context of online shopping, female users have been found to be less persuaded than male users by site information (Putrevu, 2010). The empirical findings from Shen et al., (2010) further indicated that the influence of users' attitudes, positive emotions, and group norms on intentions to use IT were more significant for men, whereas the effects of social identity and negative emotions were more important for women than for men.

More recently, Terzis and Economides (2011) have identified the constructs that affected male and female students' behavioral intention to use a computer-based assessment. The results indicated that both genders are likely to use the system as long as it is playful and its content is clear and relative to the course. Also, males were found to be motivated by their perceptions about how much useful the system is, whereas females were found to be more likely to use the system if it is easy to use. Additionally, men, compared with women, were found to perceive online stimuli as more pleasant and arousing (Bianchin and Angrilli, 2012). What is more, Venkateshet al. (2012) in their major investigation noted that gender play a significant role in moderating the impacts of social influence, facilitating conditions, performance effort expectancy, and price on behavioral intention to use IT.

Using an online survey, Kimbrough et al. (2013) analyzed responses of 381 university students about their experiences with multiple forms of mediated communication, such as social networking sites, e-mail, video calls, instant messaging, texting, and phone calls. Their results indicated that male users, compared to female users, are in general more frequent mediated communication users. Compared to male users, female users prefer and more frequently use text messaging, social media, and online video calls. Additionally, male students were found to have higher internet selfefficacy than do female students ( $\mathrm{Li}$ and Zhao, 2013). Other researchers have provided results suggesting that some aspects of user acceptance and use of

International Journal of Management and Applied Research, 2018, Vol. 5, No. 1 
information technology may be affected by gender differences, which in turn influence their behaviors and outcomes (Tsichla et al., 2014).

By using the Unified Theory of Acceptance and Use of Technology (UTAUT) and Innovation Resistance Theory, Lian and Yen (2014) develop a great model showing the moderating effect of gender in various relationships between independent variables (e.g. performance expectations, effort expectations, social expectation, and facilitating expectation) and dependent variables (e.g. behavior intention to use IT). In addition, Liebana-Cabanillas et al., (2014) investigated the moderating role of gender on acceptance of mobile-payment systems. The results showed significant differences in the relationships between the ease of use and usefulness of the new system, between usefulness, attitude and intention to use, as well as between users' trust and a favorable attitude towards its use. Using the Technology Acceptance Model 3 (TAM3), Faqih and Jaradat (2015) investigated the moderating role of gender on the adoption of mobile commerce in Jordan and the results reveal that gender does not have any moderation effect on the adoption process.

\subsection{Gender differences and online shopping adoption}

Extant evidence also suggests that men and women differ in their beliefs and behaviors regarding the use of IT-related innovations, including e-commerce (Cho, 2004; Dittmar et al., 2004; Lin and Hsieh, 2016; Rodgers and Harris, 2003; Van Slyke et al., 2010; Zhang et al., 2011). In this section, we will review the recent research into the effect of gender differences on online shopping adoption.

The "gender gap" in online shopping adoption has been fully explored in prior studies. Indeed, as early as 2002, Van Slyke et al. suggested that men compared to women are more likely to purchase online (Van Slyke et al., 2002). As indicated by Van Slyke et al. (2002), "in general, women view some forms of shopping as more of a social activity than do men", and that "if women tend to gain benefit from the social aspects of traditional shopping, web-based shopping may be viewed less favorably, thus affecting women's perceptions of the relative advantage and compatibility of webbased shopping" (p. 85). They continue, "since women enjoy the social aspect of shopping, merchants may wish to consider such features as chat rooms and threated discussions to build a shopping community and reduce the solitary nature of online shopping (p. 85). In this regard, male users were found to be about 2.5 times more likely than female users to purchase a product from a website (Zinkhan et al., 2002). In their important study, Rodgers and Harris (2003) also claimed that in almost every study has explored the gender differences in online consumer behavior, males are fundamentally the dominant users of internet channel for shopping. Furthermore, Wolin and Korgaonkar (2003) revealed that male users often surf websites for pleasure reasons, while female users surf websites for shopping reasons. In the context of e-commerce, male and female users had the same pattern in forming perceptions with respect to behavioral outcomes such as intentions to shop online (Serenko et al., 2006).

In a study in which gender differences in the context of online shopping were tested, Cyr et al. (2007) confirmed that higher levels of enjoyment have a higher positive impact on e-loyalty toward an e-services website for females compared to males.

International Journal of Management and Applied Research, 2018, Vol. 5, No. 1 
They also found that higher levels of perceived social presence have a higher positive impact on e-loyalty toward an e-services websites for females compared to males. Likewise, gender differences were found to play a moderating role in the effects of beliefs on user intentions to adopt e-commerce (Van Slyke et al., 2010). Specifically, the results indicated that relative advantage is relatively more significant for male users and that compatibility is relatively more significant for female users (Van Slyke et al., 2010). Similarly, Zhang et al., (2011) found that men were more involved in e-commerce activities than women. However, some researchers have found no statistically significant differences between men and women with regard to internet usage (e.g. Davis et al., 2014; Faqih and Jaradat, 2015; Hernández et al. 2011; Lian and Yen, 2014; Zhang, 2005). Davis et al. (2014) even argued that gender is an intentional manipulation of the anonymous body.

Some scholars have provided possible explanations for gender differences in online shopping. Dittmar et al. (2004), for example, suggest that the lack of personal interactions and face-to-face communications provided by e-vendors may be a primary reason for not doing online shopping for females. This view is very much in line with Cho's (2004) opinion, who concludes that online shopping is less comfortable and convenient for women compared to men, as women enjoy the physical evaluations of products by touching them before they buy, which in turn influences their behaviors. In addition, Rodgers and Harris (2003) explained the main reasons why female users are more dissatisfied than male users with ecommerce. The results showed that trust in e-vendors, emotional aspects, and convenience play a key role in satisfaction for male users and dissatisfaction for female users. Recently, Lin and Hsieh (2016) have argued that the gender gap in online shopping may be because of the differences in website design preferences, suggesting that if a website is not designed to match females, then female users will feel frustrated and anxious when using the website, which in turn will reduce the possibility of a purchase from the website.

\subsection{Gender differences in online trust}

Online trust is considered as a critical factor in online shopping adoption, especially when dealing with unfamiliar vendors (Pengnate and Sarathy, 2017). Yoon (2002, p. 51) argues that the uniqueness of online environments can "put pressure on Internet marketers to create a trust that is much stronger and more persistent than what is normally demanded offline".

The effect of gender difference on trust has attracted growing attention among the academia (e.g. Amin et al., 2015; Awad and Ragowsky, 2008; Beldad et al., 2016). Buchan et al. (2008) have provided considerable evidence to suggest that females, compared with males, are less likely to imagine that "most people can be trusted". Men, compared with women, were also shown to have more trusting and exchanging behaviors (Dittrich, 2015). In the context of making online purchase, studies found that trust and perceived risk significantly differ by gender (Bae and Lee, 2014; Garbarno and Strahilevitz, 2004; Rodgers and Harris, 2003). Female shoppers, in contrast to males, perceive a higher level of risk in online shopping (Bae and Lee, 2014; Garbarino and Strahilevitz, 2004; Sheehan, 2000). A further examination conducted by Park (2015) shows that men differ from women in terms of their confidence in privacy protection on the internet. In another major study in which

International Journal of Management and Applied Research, 2018, Vol. 5, No. 1 
differences across the two sexes were tested, Riedl et al. (2010) were able to provide ample evidence that men and women are different in terms of decisions to online trust. Riedl and colleagues (2010) also found that women activate more brain areas than men do to assess and trust online transactions. This was further supported by a metaanalysis conducted by Stevens and Hamann (2012). Additionally, men, compared with women, were found to perceive online stimuli as more pleasant, arousing, and trusting (Bianchin and Angrilli, 2012). Additionally, male users were found to be more satisfied with websites, and trust them more than female users (Garbarino and Strahilevitz, 2004). In addition to this, online trust was found to be more important in influencing behavioral intention for female than for males (Awad and Ragowsky, 2008).

Recent studies found that gender moderates the relationship between purchase intention and trust (Chen et al., 2015) as well as review and buying decision (Zhang et al., 2014). Under the situation of inconsistent reviews, the relationship between emotional trust and purchase intention was stronger for female consumers than male consumers (Zhang et al., 2014). Hwang (2010) found that gender moderates the adoption of e-commerce where male users are more likely to be influenced by perceived enjoyment than social norms. Moreover, the study of Beldad et al. (2016) has confirmed that gender acts as a moderator in the effect of virtual sales assistants (e.g. animate pictures and photographs of a real person) on consumer attitudes towards the product, consumer trust in e-vendors, and online purchase intentions.

\subsection{Gender differences in attitude and satisfaction with IT and e-commerce}

A number of research studies have shown that men and women have different levels of attitudes towards e-commerce (Broos, 2005; Rodgers and Harris, 2003; Schumacher and Morahan-Martin, 2001;Van Slyke et al., 2010; Wolin and Korgaonkar, 2003) and mobile payment (Faqih and Jaradat (2015; Liebana-Cabanillas et al., 2014). While Faqih and Jaradat (2015) concluded that gender does not moderate the adoption of mobile technology, Liebana-Cabanillas et al. (2014) concluded that there is a significant gender differences in terms of attitude and intention to use mobile payment. Equally, some empirical studies have reported significant gender differences with respect to customers' satisfaction and behavioral outcomes in the contexts of e-commerce ( $\mathrm{Cyr}$ and Bonanni, 2005; Gonzalez-Gomez et al., 2012; Rodgers and Harris, 2003;Serenkoet al., 2006). Therefore, the aim of this section is to provide a review on the influence of gender differences on user attitude towards, and satisfaction with internet-related activities.

In an investigation into gender differences, Wolin and Korgaonkar (2003) were able to find that men have more favorable attitudes towards site stimuli (e.g., advertisements) than women. The same findings have been reported by Parsa et al. (2011), who stated significant differences between the sexes in their beliefs about and attitudes towards online vendors. Compared to male users, female users are more likely to be influenced by negative review, and as a result, they tend to hesitate to buy a product or service that attracts negative reviews (Bae and Lee, 2014).

International Journal of Management and Applied Research, 2018, Vol. 5, No. 1 
Hasan (2010) examined gender differences in relation to the three attitudinal components (cognitive, affective, and behavioral components) towards online shopping. Although significant gender differences were found in all three components, the cognitive attitudes explained the largest differences between the genders, indicating that male users value the usefulness of online shopping more than females. In a study in which attitudes towards web advertising were empirically tested, male users were found to have more positive attitudes toward advertising on websites than women (Parsa et al., 2011). In addition, Gonzalez-Gomez et al. (2012) noted significant differences between males and females students in terms of their satisfaction with e-learning teaching.

In this regard, Rodgers and Harris, (2003) claim that trust in e-vendors, emotional aspects, and convenience play a key role in satisfaction for male users and dissatisfaction for female users. They also point out that: "there is good reason to think that emotions will interact with gender to predict satisfaction or, more to the point, dissatisfaction with e-shopping, particularly among the female consumer" (Rodgers and Harris, 2003, p. 323).

\subsection{Gender differences in website design preferences}

As pointed out, there is a considerable interest in the literature in studying gender differences regarding the use of websites, showing that men and women have different perceptions of website design. To begin with the early study of Simon (2001) who investigated gender differences in terms of visual design preferences and determined that women, in contrast to men, prefer websites with less clutter and fewer photographs. In a similar vein, females were found to react more positively than males to online stimuli that provided links to further sources of information (Phillip and Suri, 2004). Additionally, Cyr and Bonanni (2005) examined differences between male and female users in terms of preferences of website information, visual, and navigation design, with notable differences. In this context, moreover, websites designed by women were found to be different from those designed by men in terms of visual design and navigation design characteristics (Moss et al., 2006).

Tuch et al. (2010) also conducted an experiment in which 20 websites were used to discover gender differences in an online context. The results indicated that the opinions of male users about a website are more affected than female users by the website organization of information and aesthetic aspects, such as colors, as well as font size and styles. In marketing contexts, women have been found to be less encouraged than men by negative design of online messages (Putrevu, 2010). Cyr (2014) concluded that male users like peripheral cues (e.g., color and animation techniques) more than women do. Also, men and women were found to have different patterns to interpret web atmospherics (Tsichla et al., 2014). Likewise, Goodrich (2014) conducted an experimental study and revealed that women focus more strongly on the text on the website, and men focus more strongly on the images. In line with this view, in one study in which differences between men and women were examined, Park (2015) found that the visual design in web advertisements has a more powerful influence on males than on females, who tend to click on advertisements for further details. The same conclusion has been reported by Shaouf et al. (2016) who state significant differences between the sexes in the effect of web advertisements' visual

International Journal of Management and Applied Research, 2018, Vol. 5, No. 1 
design on consumers' responses. In a similar vein, the recent study of Lin and Hsien (2016) has tested gender differences related to the preferred criteria of designing websites. It found that males and females differ in this regard, with females preferring websites to be easy to use, while males like websites to be flexible.

\subsection{Gender differences in information processing strategies}

Information processing describes how information is perceived, processed, and translated into action (Massaro and Cowan, 1993). Among many models that aim to explain the effect of gender in information processing and searching, the "Selectivity Model" is a widely accepted one (Meyers-Levy 1989). According to the Selectivity Model, males are considered to be selective information processors who tend to use heuristics processing and miss subtle cues. In opposition, females are considered to be comprehensive information processors who consider both subjective and objective product attributes and respond to subtle cues (Meyers-Levy 1989). Since its appearance a long time ago, the Selectivity Model has become one of the most frequently referenced and powerful theories that explain gender differences in information processing (e.g. Chua and Murray, 2015; Meyers-Levy, 1989; Nelson and Vilela, 2012; Okazaki and Hirose, 2009; Vilela and Nelson, 2016).

Based on the selectivity model, we can suppose that viewing an internet offer with different information types will require different information processing strategies and pay attention to it differently.

In the contexts of IT and e-commerce, researchers have adopted the consumer behavior selectivity theory, exploring how external stimuli influence humans' responses across the two sexes. To exemplify, Richard et al. (2010) explained the Selectivity Model in relation to the effects of e-atmosphere and online experience on shopper behavior. Riedlet al. (2010) also employed the Selectivity Model to examine gender differences in terms of the participants' decisions related to online trust. More recently, Goodrich (2014) adopted the same theory to discover how male and female users form their attitudes towards design elements of web advertisements. Shaouf et al. (2016) replicated and explained gender differences regarding the influence of online advertisements' visual design on shopper attitudes and behavioral intentions. Based on the assumption of Meyers-Levy's (1989) theory, Tsichlaet al. (2014) also tested the moderating role of gender in the relationship between online atmospherics and users' attitudes towards the website and the brand. The Selectivity Model has also been validated in the context of cause-related marketing (Vilela and Nelson, 2016). The studies of Chua and Murray (2015) and Park (2015) have also embraced the Selectivity Model to examine differences among men and women associated with marketing communication strategies. Additionally, men are often considered to use more of the cognitive brain structure during information processing, while women use more of the affective structure (Riedl et al., 2010). Females are generally considered to be more left hemisphere-dominant and men are more right hemisphere-dominant (Goodrich, 2014). 


\section{Conclusion}

In the recent years, the number of male and female Internet users has increased dramatically. This has led to an increase in the e-commerce industry among the two sexes (Cyr, 2014). Considerable research has been devoted to understanding the impact of gender differences on online shopping adoption (Cho, 2004; Cyr et al., 2007; Dittmar et al., 2004; Lin and Hsieh, 2016; Rodgers and Harris, 2003; Van Slyke et al., 2010; Zhang et al., 2011). Theories of IT adoption (e.g. TAM and UTAUT) have been widely explored and adapted to accommodate the unique virtual character of online shopping (Amin et al., 2015;Awad and Ragowsky, 2008; Lian and Yen, 2014; Terzis and Economides, 2011; Venkatesh and Morris, 2000). Models,such as the Selectivity Model, have enjoyed widespread application including in the e-commerce realm (Meyers-Levy and Loken, 2015;Richardet al., 2010; Shaouf et al., 2016; Tsichlaet al., 2014). That is to say, there is a considerable interest in the literature in studying the influence of gender regarding the use of IT and its related innovations, including e-commerce. Thus, the aim of this article was to provide a review on the effect of gender differences on IT adoption and related behaviors (of online shopping adoption, online trust, attitude and satisfaction with e-commerce, website design preferences, and information processing strategies).

According to the present review, men are more likely to try a new IT than women (Schumacher and Morahan-Martin, 2001; Van Slyke et al., 2002; Weiser, 2000), although the findings have been inconclusive (Bigne et al., 2005; Serenko et al., 2006). The findings of empirical research also indicated that perceived usefulness (PU) is more significant for men, while perceived ease of use (PEOU) is more significant for women (Amin et al., 2015; Terzis and Economides, 2011;Venkatesh and Morris, 2000). Accordingly, online trust was found to be more important in influencing behavioral intention for female than for males (Awad and Ragowsky, 2008).Findings from the current review also indicated that, in general, men are more likely to use websites for shopping (Rodgers and Harris, 2003; Zinkhan et al., 2002). In addition, females consider some methods of shopping as more of a social activity than do males (Van Slyke et al., 2002). It was believed that inadequate perceived emotional benefits may be an underlying reason why women are less involved in ecommerce activity (Rodgers and Harris, 2003).

In the literature, online trust is considered as an important dimension in the online shopping context. It is widely believed that online shoppers are often uncertain about the risk related to e-transactions. Consumers are also concerned with legitimacy of online vendors and authenticity of products or services. Therefore, in order to ensure that online transactions are completed, e-shoppers must be confident and trusting in evendors (Pengnate and Sarathy, 2017; Porter et al., 2012; Yoon, 2002). The effect of gender difference on e-trust has attracted considerable attention in the literature, indicating that male users express higher levels of trust in internet-related activities than female users (Garbarno and Strahilevitz, 2004; Park, 2015; Rodgers and Harris, 2003). Although some empirical studies have reported significant gender differences relating to customers' attitude and satisfaction with internet-based activities (e.g. Hasan, 2010; Wolin and Korgaonkar, 2003), findings from other studies reported the opposite, showing no significant gender differences in these responses (Parsa et al., 2011; Lian and Yen, 2014).

International Journal of Management and Applied Research, 2018, Vol. 5, No. 1 
Women, in contrast to men, were found to prefer websites with less clutter and fewer photographs (Simon, 2001). Websites designed by women were different from those designed by men in terms of visual design and navigation design. Men are more drawn to action in the form of animations. Men and women also differed in their principles related to the design of websites (Moss et al., 2006). Additionally, women enjoyed physical evaluations of products more than men (Cho, 2004). According to the Selectivity Model (Meyers-Levy, 1989), females tend to be more comprehensive processors than males, while men are more selective information processors.

\subsection{Limitations and directions for future research}

Although empirical research on the use of IT and related behaviors has flourished in recent years, there remains considerable scope for new investigations as the use of the Internet shifts and continues to expand. For example, there is a need to better understand the impact of website design elements (e.g. visual, information, and navigation design) online trust across gender. Although the empirical studies (e.g. Cyr, 2014; Ganguly et al., 2010) found that the relationship between website design and online trust is moderated by culture, they fail to fully acknowledge the significant role of demographic characteristics (e.g., gender), which play a vital role in the field of e-commerce (Park, 2015). Therefore, exploring the moderating effect of gender in effects of website design on online trust is an avenue for future research.

While Hasan (2016) has recently explained how users' perceptions of website design influence negative feelings (perceived irritation), we are given no explanation of the potential impact of different website designs on emotional responses among male and female users. A further study with more focus on the effect of website design on user emotional responses (e.g. pleasure and arousal) is therefore suggested. In this regard, Cyr and Bonanni, (2005, p. 566) claim that "the design of a website may have an impact on user preferences, which in turn may produce differing reactions between men and women." Cyr (2014) highlighted the importance of investigating gender difference related to the effect of website design on shopper responses, due to its potential contribution to both researchers and practitioners. Therefore, research exploring the moderating role of gender in the effect of website design on online shoppers' emotions is needed.

According to Sun et al. (2010) and Venkatesh and Morris (2000), investigating gender differences in the process of decision making will provide better insights and results than examining their effects on shopping outcomes. By applying the Selectivity model, it might be convincingly argued that male users will give more attention to whatever is attractive and interesting on websites than women, and therefore men are more likely to judge websites based on peripheral cues such as images, colors, and animation. In future research, it is also interesting to analyze the effect size of cognitive responses (e.g. beliefs) versus affective responses (emotions and moods) on attitudes and online purchase intention across gender.

In the contexts of IT and e-commerce, past research has largely investigated the effect of site stimuli on user behavioral intention such as purchase intention or intentions to use IT (Ong and Lai, 2006; Shaouf et al., 2016; Shen et al., 2010). However, actual

International Journal of Management and Applied Research, 2018, Vol. 5, No. 1 
behavior is considered to be the final outcome of online stimuli. Thus, exploring how different web stimuli affect actual behaviours is an avenue for future research.

As the use of emotional cues is gaining prominence and thus deserves future investigation. This may include different preferences in the use of affective elements in website design such as social presence, and how they differ between men and women. It is valuable to introduce such an investigation in IT and e-shopping research, as it will offer a better understanding of how to link web stimuli to marketing goals (Cyr, 2014).

Finally, the review of the literature shows that the majority of previous studies have adopted university students (in the age bracket of 18-27 years) to investigate gender differences in the use of IT and related innovations (Braak, 2004; Kimbrough et al., 2013; Li and Zhao, 2013; Schumacher and Morahan-Martin, 2001). Thus, future research can expand previous studies by using samples with a variety in age and educational backgrounds, so as to more fully understand gender differences in IT adoption and use, attitudes toward online shopping, satisfaction with IT and ecommerce, preferences of website design, and information processing strategies.

The current paper contributes to the existing literature by offering guidelines for researchers and practitioners as to what outlines gender differences in several important areas, including IT and e-commerce adoption.

\section{References}

1. Amin, M., Rezaei, S. and Tavana, F. S. (2015), "Gender differences and consumer's repurchase intention: the impact of trust propensity, usefulness and ease of use for implication of innovative online retail", International Journal of Innonation and Learning, Vol. 17, No.2, pp. 217233.https://doi.org/10.1504/IJIL.2015.067409

2. Awad, N. F. and Ragowsky, A. (2008), "Establishing trust in electronic commerce through online word of mouth: an examination across genders", Journal of Management Information Systems, Vol. 24, No. 4, pp. 101121.https://doi. 10.2753/MIS0742-1222240404

3. Bae, S. and Lee, T. (2011), “Gender differences in consumers' perception of online consumer reviews", Electronic Commerce Research, Vol. 11, No. 2, pp. 201-214. https://doi. 10.1007/s10660-010-9072-y

4. Beldad, A., Hegner, S. and Hoppen, J. (2016),“The effect of virtual sales agent (VSA) gender-product gender congrauence on product advice credibility, trust in VSA and online vendor, and purchase intention", Computers in Human Behavior, Vol. 60, pp. 62-72.https://doi.org/10.1016/j.chb.2016.02.046

5. Bianchin, M. and Angrilli, A. (2012), “Gender differences in emotional responses: a psychophysiological study", Physiology \& Behavior, Vol. 105, No. 4, pp. 952-932. https://doi.org/10.1016/j.physbeh.2011.10.031

International Journal of Management and Applied Research, 2018, Vol. 5, No. 1 
6. Bigne, E., Ruiz, C. and Sanz, S. (2005),"The impact of internet user shopping patterns and demographics on consumer mobile buying behaviour", Journal of Electronic Commerce Research, Vol. 6, No. 3, pp. 193-209.

7. Braak, J. (2004), "Domains and determinants of university students' self-perceived computer competence" ,Computers \& Education,Vol.43, No. 3, pp. 299312.https://doi.org/10.1016/j.compedu.2003.09.006

8. Broos, A. M. A. (2005), "Gender and information and communication technologies (ICT) anxiety: male self-assurance and female hesitation", Cyber Psychology \& Behavior, Vol. 8, No. 1, pp. 2131.https://doi.org/10.1089/cpb.2005.8.21

9. Buchan, N. R., Croson, R. T. and Solnick, S. (2008), "Trust and gender: an examination of behavior and beliefs in the investment game",Journal of Economic Behavior \& Organization, Vol. 68, No. 3, pp. 466476.https://doi.org/10.1016/j.jebo.2007.10.006

10. Chen, Y, Yan, X, Fan, W. and Gordon, M. (2015), "The joint moderating role of trust propensity and gender on consumers' online shopping behavior", Computers in Human Behavior, Vol. 43, pp. 272283.https://doi.org/10.1016/j.chb.2014.10.020

11. Cho, J. (2004), "Likelihood to abort an online transaction: influences from cognitive evaluations, attitudes, and behavioral variables",Information and

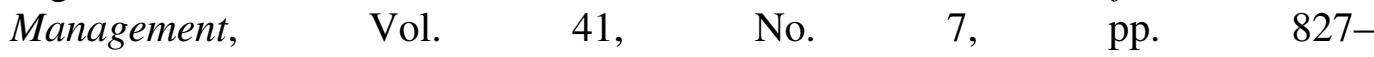
838.https://doi.org/10.1016/j.im.2003.08.013

12. Chua, S. M. and Murray, D. W. (2015), "How toxic leaders are perceived: gender and information-processing",Leadership \& Organization Development Journal, Vol. 36, No. 3, pp. 292-307.https://doi.org/10.1108/LODJ-06-2013-0076

13. Cyr, D. (2014),"Return visits: a review of how web site design can engender visitor loyalty", Journal of Information Technology, Vol. 29, No. 1, pp. 126.https://link.springer.com/article/10.1057/jit.2013.25

14. Cyr, D. and Bonanni, C. (2005),"Gender and website design in e-business", International journal of Electronic Business, Vol. 3, No. 6, pp. 565582.https://doi.org/10.1504/IJEB.2005.008536

15. Cyr, D., Hassanein, K., Head, M. and Ivanov, A. (2007),"The role of social presence in establishing loyalty in e-service environments", Interacting with Computers, Vol. 19, No. 1, pp. 4356.https://doi.org/10.1016/j.intcom.2006.07.010

16. Davis, R., Lang, B. and Diego, J. S. (2014), "How gender affects the relationship between hedonic shopping motivation and purchase intentions?", Journal of Consumer Behaviour, Vol. 13, No. 1, pp. 18-30. https://doi.org/10.1002/cb.1450

17. Dittmar, H., Long, K. and Meek, R. (2004),"Buying on the internet: gender differences in on-line and conventional buying motivations",Sex Roles, Vol. 50, No. 5/6, pp. 423-444.https://doi.org/10.1023/B:SERS.0000018896.35251.c7 
18. Dittrich, M. (2015),"Gender differences in trust and reciprcity: evidence from a large-scale experiment with heterogeneous subjects",Applied Economics, Vol. 47, No. 36, pp. 3825-3838.https://doi.abs/10.1080/00036846.2015.1019036

19. Hernández, B.; Jiménez, J. and Martín, M. J. (2011), “Age, gender and income: do they really moderate online shopping behaviour?", Online Information Review, Vol. 35 Issue: 1, pp.113-133, https://doi.org/10.1108/14684521111113614

20. Faqih, K. M.S. (2016),“A empirical analysis of factors predicting the behavioral intention to adopt internet shopping technology among non-shoppers in a developing country context: dos gender matter?", Journal of Retailing and Consumer Services, Vol. 30, pp. 140-164. https://doi.org/10.1016/j.jretconser.2016.01.016

21. Faqih, K.M.S. and Jaradat, M.R.M. (2015),"Assessing the moderating effect of gender differences and individualism-collectivism at individual-level on the adoption of mobile commerce technology: TAM3 perspective", Journal of Retailing and Consumer Services, Vol. 22, pp. 37-52. https://doi.org/10.1016/j.jretconser.2014.09.006

22. Ganguly, B., Dash, S. B., Cyr, D. and Head, M. (2010),"The effects of website design on purchase intention in online shopping: the mediating role of trust and the moderating role of culture", International Journal of Electronic Business, Vol. 8, No. 4/5, pp. 302-330.https://doi/abs/10.1504/IJEB.2010.035289

23. Garbarino, E. and Strahilevitz, M. (2004), "Gender differences in the perceived risk of buying online and the effects of receiving a site recommendation", Journal of Business Research, Vol. 57, No. 7, pp. 768-775.https://doi.org/10.1016/S01482963(02)00363-6

24. Gonzalez-Gomez, F., Guardiola, J., Martin-Rodriguez, O. and Montero-Alonso, M. A. (2012), “Gender differences in e-learning satisfaction”, Computers \& Education, Vol. 58, No. 1, pp. 290.https://doi.org/10.1016/j.compedu.2011.08.017

25. Goodrich, K. (2014), “The gender gap: Brain-processing differences between the sexes shape attitudes about online advertising",Journal of Advertising Research, Vol. 54, No. 1, pp. 32-43.https://doi.10.2501/JAR-54-1-032-043

26. Hasan, B. (2010), "Exploring gender differences in online shopping attitude", Computers in Human Behavior, Vol. 26, No. 4, pp. 597-601. https://doi.org/10.1016/j.chb.2009.12.012

27. Hasan, B. (2016), "Perceived irritation in online shopping: the impact of website design characteristics", Computers in Human Behavior, Vol. 54, pp. 224230.https://doi.org/10.1016/j.chb.2015.07.056

28. Hwang, Y. (2010), “The moderating effects of gender on e-commerc systems adoption factors: an empirical investigation", Computers in Human Behavior, Vol. 26, No. 6, pp. 1753-1760. https://doi.org/10.1016/j.chb.2010.07.002

29. International Telecommunications Union (2017), ICT Facts and Figures 2017, [Online] available from: https://www.itu.int/en/ITU- 
D/Statistics/Documents/facts/ICTFactsFigures2017.pdf [accessed on 1 March 2018].

30. Kimbrough, A. M., Guadagno, R. E., Muscanell, N. L. and Dill, J. (2013), “Gender diffrences in mediated communication: women connect more than do men", Computers in Human Behavior, Vol. 29, pp. 896-900. https://doi.org/10.1016/j.chb.2012.12.005

31. Li, Y. and Zhao, Q. (2013), "Effect of pesonal characteristics on chinese high school students' internet sself-efficacy", Sccial Behavior and Personality: an International Journal, Vol. 41, No. 10, pp. 17171724.https://doi.org/10.2224/sbp.2013.41.10.1717

32. Lian, J. W. and Yen, D. C. (2014), “Online shopping drivers and barriers for older adults: Age and gender differences",Computers in Human Behvior, Vol. 37, pp. 133-143.https://doi.org/10.1016/j.chb.2014.04.028

33. Liebana-Cabanillas, F. J., Sanchez-Fernandez, J. and Munoz-Leiva, F. (2014), "Role of gender on acceptance of mobile payment", Industrial Management \& Data Systems, Vol. 114, No. 2, pp. 220-240. https://doi.org/10.1108/IMDS-03-2013-0137

34. Lin, C. J. and Hsieh, T. L. (2016), "Exploring the design criteria of website interfaces for gender",International Journal of Industrial Ergonomics, Vol. 53, pp. 306-311.https://doi.org/10.1016/j.ergon.2016.02.002

35. Massaro, D. W. and Cowan, N. (1993), "Information processing models: Microscopes of the mind",Annual Review of Psychology, Vol. 44, pp. 383425.https://doi.org/10.1146/annurev.ps.44.020193.002123

36. Meyers-Levy, J. (1989), "Gender differences in information processing: A selective interpretation". In Cafferata, P. and Tybout, A. (eds.), Cognitive and affective responses to advertising. Lexington: Lexington Books, pp. 219-260.

37. Meyers-Levy, J. and Loken, B. (2015), "Revisiting gender differences: what we know and what lies ahead",Journal of Consumer Psychology, Vol. 25, No. 1, pp. 129-149.https://doi.org/10.1016/j.jcps.2014.06.003

38. Morahan-Martin, J. (1998), “The gender gap in Internet use: why men use the Internet more than women-a literature review", Cyber Psychology and Behavior, Vol.1, No. 1, pp. 3-10.https://doi.org/10.1089/cpb.1998.1.3

39. Moss, G., Gunn, R., and Heller, J. (2006), "Some men like it black, some women like it pink: consumer implications of differences in male and female website design",Journal of Consumer Behavior, Vol. 5, No. 4, pp. 328341.https://doi.org/10.1002/cb.184

40. Mulrow, C. D. (1994), "Systematic reviews-rationale for systematic reviews", British Medical Journal,Vol. 309, No. 6954, pp. 597599.https://doi.org/10.1136/bmj.309.6954.597

41. Nelson, M. R. and Vilela, A. M. (2012),"Is the Selectivity Hypothesis still relevant? A review of gendered persuasive and processing of advertising messaes", in Otnes, C. C. and Zayer, L. T. (eds.) Gender, culture, and consumer behavior. New York: Routledge. 
42. Okazaki, S. and Hirose, M. (2009), "Does gender affect media choice in travel information search? On the use of mobile internet", Tourism Management, Vol. 30, No. 6, pp. 794-804.https://doi.org/10.1016/j.tourman.2008.12.012

43. Ong, C. S. and Lai, J. Y. (2006), "Gender differences in perceptions and relationships among dominants of e-learing acceptance", Computers in Human Behavior, Vol. 22, No. 5, pp. 816-829.https://doi.org/10.1016/j.chb.2004.03.006

44. Park, Y. J. (2015), "Do men and women differ in privacy? Gendered privacy and (in) equality in the Internet",Computers in Human Behavior, Vol. 50, pp. 252258.https://doi.org/10.1016/j.chb.2015.04.011

45. Parsa, F., Tomic, I., Angelidis, J. and Ibrahim, N. (2011), "Gender effects on ecommerce",Journal of Academy of Business and Economics, Vol. 11, No. 4, pp. 219-223.

46. Pengnate, S. and Sarathy, R. (2017), "An experimental investigation of the influence of website emotional design features on trust in unfamiliar online vendor"s, Computers in Human Behavior, Vol. 67, pp. 4960.https://doi.org/10.1016/j.chb.2016.10.018

47. Phillip, M. V. and Suri, R. (2004), "Impact of gender differences on the evaluation of promotional emails",Journal of Advertising Research, Vol. 25, No. 2, pp. 144-159.https://doi.org/10.1017/S0021849904040383

48. Porter, C. E., Donthu, N. and Baker, A. (2012), "Gender differences in trust formation in virtual communities", Journal of Marketing Theory and Practice, Vol. 20, No. 1, pp. 39-58.https://doi.abs/10.2753/MTP1069-6679200103

49. Putrevu, S. (2010), "An examination of consumer responses toward attribute- and goal-framed messages",Journal of Advertising, Vol. 39, No. 3, pp. 5-24. https://doi.org/10.2753/JOA0091-3367390301

50. Richard, M., Chebat, J. C., Yang, Z. and Putrevu, S. (2010), "A proposed model of online consumer behavior: Assessing the role of gender", Journal of Business Research, Vol. 63, No. 9/10, pp. 926934.https://doi.org/10.1016/j.jbusres.2009.02.027

51. Riedl, R., Hubert, M. and Kenning, P. (2010), “Are there neural gender differences in online trust? an FMRI study on the perceived trustworthiness of eBay offers",MIS Quarterly, Vol. 34, No. 2, pp. 397428.https://dl.acm.org/citation.cfm?id=2017469

52. Rodgers, S. and Harris, M. A. (2003), "Gender and e-commerce: an explortory study",Journal of Advertising Research, Vol. 43, No. 3, pp. 322329.https://doi.org/10.1017/S0021849903030307

53. Sanchez-Franco, M. J. (2006), "Exploring the influence of gender on the web usage via partial least squares", Behavior \& Information Technology, Vol. 25, No. 1, pp. 19-36.https://doi.abs/10.1080/01449290500124536

54. Schumacher, P. and Morahan-Martin, J. (2001), "Gender, interent and computer attitudes and experiences", Computers in Human Behavior, Vol. 17, No. 1, pp. 95-110.https://doi.org/10.1016/S0747-5632(00)00032-7

International Journal of Management and Applied Research, 2018, Vol. 5, No. 1 
55. Serenko, A., Turel, O. andYol, S., (2006), "Moderating roles of user demographics in the American customer satisfaction model within the context of mobile services", Journal of Information Technology Management, Vol. 17, No. 4, pp. 20-32.

56. Shaouf, A., Lü, K. and Li, X. (2016), "The effect of web advertising visual design on online purchase intention: An examination across gender", Computers

in Human Behavior, Vol. 60, pp. 622-634.

https://doi.org/10.1016/j.chb.2016.02.090

57. Sheehan, K. B. (2000) "An investigation of gender differences in on-line privacy concerns and resultant behaviors",Journal of Direct Marketing, Vol. 13, No. 4, pp. 24-38.https://doi.org/10.1002/(SICI)1520-6653(199923)13:4<24::AIDDIR3 > 3.0.CO;2-O

58. Shen, A. X, Lee, M. K., Cheung, C. M. and Chen, H. (2010), “Gender differences in intentional social action: we-intention to engage in social network-facilitated team collaboration", Journal of Information Technology, Vol. 25, No. 2, pp. 152169.https://doi.org/10.1057/jit.2010.12

59. Simon, S. J. (2001), "The impact of culture and gender on web sites: an empirical study",The Data Base for Advances in Information Systems, Vol. 32, No. 1, pp. 18-37. https://doi.org/10.1145/506740.506744

60. Slavin, R. E. (1986), "Best-evidence synthesis: an alternative to meta-analytic and traditional reviews", Educational Researcher, Vol.15, No. 9, pp. 511.https://doi.abs/10.3102/0013189X015009005

61. Stevens, J. S. and Hamann, S. (2012), "Sex differences in brain activation to emotional stimuli: a meta-analysis of neuroimaging studies", Neuropsychologia, Vol. 50, No. $\quad 7, \quad$ pp. 1593.https://doi.org/10.1016/j.neuropsychologia.2012.03.011

62. Sun, Y., Lim, K. H., Jiang, C., Peng, J. Z. and Chen, X. (2010), "Do males and females think in the same way? an empirical investigation on the gender differences in Web advertising evaluation",Computers in Human Behavior, Vol. 26, No. 6, pp. 1614-1624.https://doi.org/10.1016/j.chb.2010.06.009

63. Terzis, V. and Economides, A.A. (2011), "Computer based assessment: gender differences in perceptions and acceptance",Computers in Human Behavior, Vol. 27, No. 6, pp. 2108-2122.https://doi.org/10.1016/j.chb.2011.06.005

64. Tranfield, D., Denyer, D. and Smart, P. (2003), "Towards a methodology for developing evidence-informed management knowledge by means of systematic review", British Journal of Management, Vol. 14, pp. 207222.https://doi.org/10.1111/1467-8551.00375

65. Tsichla, E., Hatzithomas, L. and Boutsouki, C. (2014), "Gender differences in the interpretation of web atmospherics: A selectivity hypothesis approach",Journal of Marketing Communications, Vol. 22, No. 6, pp. 1-24. https://doi.org/10.1080/13527266.2014.903507

66. Tuch, A. N., Bargas-Avila, J. A. and Opwis, K. (2010), "Symmetry and aesthetics in website design: It's a man's business", Computers in Human

International Journal of Management and Applied Research, 2018, Vol. 5, No. 1 
Behavior, Vol. 26, $\quad$ No. $\quad 6, \quad$ pp. 1837.https://doi.org/10.1016/j.chb.2010.07.016

67. Van Slyke, C., Belanger, F., Johnson, R. D. and Hightower, R. (2010), "Genderbased differences in consumer e-commerce adoption", Communications of the Assocation for Information Systems, Vol. 26, No. 1, pp. 17-34.

68. Van Slyke, C., Comunale, C.L. and Belanger, F., (2002), "Gender differences in perceptions of web-based shopping", Communications of the ACM, Vol. 45, No. 7, pp. 82-86.https://doi.10.1145/545151.545155

69. Venkatesh, V. and Morris, M. G. (2000), "Why don't men ever stop to ask for directions? Gender, social influence, and their role in technology acceptance and usage behavior", MIS Quarterly, Vol. 24, No. 1, pp. 115-139.h

70. Venkatesh, V., Thong, J. and Xu, X. (2012), "Consumer acceptance and use of information technology: extending the unified theory of acceptance and use of technology", MIS Quarterly, Vol. 36, No. 1, pp. 157-178.

71. Vilela, A. M. and Nelson, M. R. (2016), "Testing the Selectivity Hypothesis in cause-related marketing among Generation Y: [When] Does gender matter for short- and long-term persuasion?", Journal of Marketing Communications, Vol. 22, No. 1, pp. 18-35.https://doi.org/10.1080/13527266.2013.841272

72. Weiser, E. B. (2000), "Gender differences in Internet use patterns and Internet application preferences: a two-sample comparison", Cyber Psychology and Behavior, Vol.3, No. 2, pp. 167-178. https://doi.org/10.1089/109493100316012

73. Wilder, G., Makie, D. and Cooper, J. (1985), "Gender and computers: two surveys of computer-related attitudes", Sex Roles, Vol.13, No. 3-4, pp. 215-228. https://doi.org/10.1007/BF00287912

74. Wilson, S. R. (2002), Seeking and resisting compliance:why peopoe say what they do when trying to influence others. Thousand Oaks: Sage Publications.

75. Wolin, L. D. and Korgaonkar, P. (2003), "Web advertising: gender differences in beliefs, attitudes and behavior",Internet Research: Electronic Networking Applications and Policy, Vol. 13, No. 5, pp. 375-385. https://doi.org/10.1108/10662240310501658

76. Yoon, S. (2002), "The antecedents and consequences of trust in online-purchase decisions",Journal of Interactive Marketing, Vol. 16, No. 2, pp. 47-63. https://doi.org/10.1002/dir.10008

77. Zhang, Y. (2005), "Age, gender and internet attitudes among employees in the business world", Computers in Human Behavior, Vol. 21 No. 1, pp. 1-10. https://doi.org/10.1016/j.chb.2004.02.006

78. Zhang, K. Z.K., Cheung, C. M.K. and Lee, M.K.O. (2014), "Examining the moderating effect of inconsistent reviews and and its gender differences on consumers' online shopping decision", International Journal of Information Management, Vol. 34, pp. 89-98.https://doi.org/10.1016/j.ijinfomgt.2013.12.001

79. Zhang, J., Mandl, H. and Wang, E. (2011), "The effect of vertical-horizontal individualism-collectivism on acculturation and the moderating role of gender",

International Journal of Management and Applied Research, 2018, Vol. 5, No. 1 
The Impact of Gender Differences on Adoption of Information Technology and Related Responses: A Review

International Journal of Intercultral Research, Vol. 35, No. 1, pp. 124134.https://doi.org/10.1016/j.ijintrel.2010.09.004

80. Zinkhan, G. M., Fox, R. J. and Kwak, H. (2002), "What products can be successfully promoted and sold via the internet?", Journal of Advertising Research, Vol. 42, No. 1, pp. 23-38.https://doi.10.2501/JAR-42-1-23-38

International Journal of Management and Applied Research, 2018, Vol. 5, No. 1 